Smith, E. E. B., Mills, G. T., Bernheimer, H. P. \& Austrian, R. (1959). J. gen. Microbiol. 20, 654-669

\title{
A Study of some Enzymes in Extracts of a Non-Capsulated Strain of Pneumococcus Concerned with Uridine Pyrophosphoglycosyl Metabolism
}

\author{
By EVELYN E. B. SMITH* AND G. T. MILLS* \\ Department of Biochemistry, University of Glasgorw, Scotland
}

\author{
AND By HARRIET P. BERNHEIMER AND R. AUSTRIAN \\ Department of Medicine, State University of Nerw York College of Medicine \\ at New York City, Brooklyn 3, N.Y., U.S.A.
}

SUMMARY : Disruption of cells in a Mickle disintegrator in the presence of $\boldsymbol{n}$-octanol is described as a method for obtaining extracts from the non-capsulated strain $\mathbf{R 1 9}$ of Streptococcus pneumoniae, derived from a strain of capsular type II. Such extracts were fractionated with ammonium sulphate in the presence of Celite and the distribution in the various fractions so obtained of a number of enzymes concerned with uridine pyrophosphoglycosyl metabolism was studied. Celite in the presence of ammonium sulphate was effective in removing organic pyrophosphatases, phosphatases acting upon uridine pyrophosphoglycosyl compounds and a reduced triphosphopyridine nucleotide (TPNH) oxidase.

A reduced diphosphopyridine nucleotide (DPNH) oxidase was concentrated by fractionation with ammonium sulphate and the uridyltransferases acting upon uridine pyrophosphoglucose (UPPG) and uridine pyrophosphoacetylglucosamine (UPPAG) were obtained as partially separated entities. Uridine pyrophosphogalactose (UPPgalactose) and guanosine pyrophosphomannose (GPPM) were not pyrophosphorylysed by the unfractionated material or by any of the fractions obtained.

UPPgalactose-4-epimerase and phosphogalactosyl uridyl transferase were present in the extracts under study, these enzymes being involved in the conversion of galactose-1-phosphate to glucose-1-phosphate. Such extracts also converted mannose to glucose phosphate without the participation of UPPG.

Evidence is provided for the presence of a diphosphopyridine (DPN) linked UPPG dehydrogenase which is capable of forming uridine pyrophosphoglucuronic acid (UPPGA) from UPPG. The UPPGA so formed was separated by ion-exchange chromatography. The extracts used did not catalyse the epimerization of UPPGA to uridine pyrophosphogalacturonic acid (UPPgalacturonic acid) as do extracts of a strain of capsulated type I pneumococcus. An examination of the cellular content of uridine nucleotides in relation to the bacterial growth curve showed that UPPGA did not accumulate in significant amounts until the organisms of this strain had reached the stationary phase.

In a comparison of the uridine pyrophosphoglycosyl metabolism of certain strains of capsulated and non-capsulated pneumococci (Smith, Mills \& Harper, $1957 a$ ), cell-free enzyme systems were obtained by grinding the organisms in the presence of ballotini and buffers of specific $\mathrm{pH}$ values. The extracts so obtained were shown to contain the enzymes uridyl transferase, glucose-6-

* Present address: Department of Medicine, State University of New York College of Medicine at New York City, Brooklyn 3, N.Y., U.S.A. 
phosphate dehydrogenase, hexokinase, nucleoside diphosphokinase, phosphoglucomutase and inorganic pyrophosphatase. In a subsequent publication (Smith, Mills, Bernheimer \& Austrian, 1958a) it was reported that, although disruption of the organisms with ballotini in the Mickle disintegrator caused considerable inactivation of many of the above enzymes, the addition of small amounts of $n$-octanol during such treatment considerably decreased this loss of activity. Extracts prepared in this manner from the non-capsulated strain $\mathbf{R} 19$ of Streptococcus pneumoniae, derived from a capsulated type II organism, were shown to convert UPPG to UPPGA (Smith et al. 1958a).

It is known that galactose and mannose are fermented actively by various strains of pneumococcus (Jürgens, 1937; Langvad-Nielsen, 1944) and also that galactose may be utilized by type III pneumococci for the synthesis of capsular polysaccharide (Bernheimer, 1953). In view of these findings, it was decided to investigate the enzyme systems involved in the metabolism of these two hexoses, with particular reference to their conversion to glucose or to glucose phosphates. To achieve this end, a method of fractionation of pneumococcal extracts has been developed and the separation of a number of enzymes concerned with uridine pyrophosphoglycosyl metabolism has been achieved.

\section{METHODS}

The organism used was a non-capsulated strain of pneumococcus, R 19 (kindly supplied by Dr R. D. Hotchkiss, The Rockefeller Institute for Medical Research, New York, U.S.A.) derived from the capsulated type II strain, D39S. Glucuronic acid, glucose and rhamnose are the constituents of type II capsular polysaccharide (Butler \& Stacey, 1955).

Uridine triphosphate (UTP) was obtained from Pabst Laboratories, Milwaukee, Wis., U.S.A.

Adenosine triphosphate (ATP), uridine pyrophosphoglucose (UPPG), uridine pyrophosphoglucuronic acid (UPPGA), triphosphopyridine nucleotide (TPN, $75 \%$ purity), reduced TPN (TPNH, $75 \%$ purity) and $\alpha$-galactose1-phosphate were obtained from Sigma Chemical Company, St Louis, Mo., U.S.A.

Diphosphopyridine nucleotide (DPN, 95\% purity) and reduced DPN (DPNH, 65\% purity) were obtained from C. F. Boehringer and Soehne, Mannheim, West Germany.

${ }^{32} \mathrm{P}$ labelled glucose-1-phosphate was prepared from ${ }^{14} \mathrm{C}$ labelled starch (Radiochemical Centre, Amersham, England) by the method of McCready \& Hassid (1955) with rabbit muscle phosphorylase prepared by the method of Green \& Cori (1943).

${ }^{14} \mathrm{C}$ labelled UPPG was prepared by the method of Munch-Petersen, Kalckar, Cutolo \& Smith (1953) employing ${ }^{14} \mathrm{C}$ labelled glucose-1-phosphate, uridyl transferase prepared by the method of Munch-Petersen (1955) and inorganic pyrophosphatase prepared by the method of Heppel \& Hilmoe (1955). The UPPG was separated by paper chromatography in the ethanol/ammonium acetate solvent of Paladini \& LeLoir (1952).

Mannose-1-phosphate was synthesized by the method of Colowick (1938). 
Bacto Brain Heart Infusion was obtained from Difco Laboratories, Detroit, Michigan, U.S.A.

UPPG and uridine pyrophosphoacetylglucosamine (UPPAG) were prepared from yeast by the method of Caputto, LeLoir, Cardini \& Paladini (1950) and separated by ion exchange and paper chromatography.

Guanosine pyrophosphomannose (GPPM) was isolated from yeast by the method of Cabib \& LeLoir (1954).

UPPG dehydrogenase was isolated from calf liver by the method of Strominger, Maxwell, Axelrod \& Kalckar (1957).

Cultivation and harvesting of pneumococci was carried out in the following manner. The organism was grown in $\mathbf{5 0 0} \mathrm{ml}$. Difco brain heart infusion medium $(3.7 \%, \mathrm{w} / \mathrm{v} ; \mathrm{pH} 7 \cdot 4)$ containing $0.1 \%$ Neopeptone. After incubation overnight, glucose was added to a final concentration of $1 \%(\mathrm{w} / \mathrm{v})$ and the lactic acid formed on subsequent incubation was neutralized with $3 \mathrm{~N}-\mathrm{NaOH}$ according to the method described by MacLeod \& Krauss (1947); all incubations were carried out at $36 \cdot 5^{\circ}$. The organisms were collected by centrifugation at $1500 \mathrm{~g}$ for $20 \mathrm{~min}$. at $0^{\circ}$, at a point in the logarithmic phase of growth determined by titration with $\mathrm{NaOH}$. Figure 1 shows a typical growth curve for a standard inoculum of strain $\mathrm{R} 19$, expressed in terms of the amount of $\mathrm{NaOH}$ required for neutralization of the lactic acid produced; the points at which the organisms were harvested are shown in the figure.

Paper chromatography of nucleotides was carried out with the neutral ethanol/ammonium acetate solvent of Paladini \& LeLoir (1952); sugar chromatography was carried out in the same ethanol/ammonium acetate solvent and in the butanol/acetic acid/water solvent of Partridge (1948) on Whatman no. 1 paper. The aniline hydrogen phthalate reagent of Partridge (1949) was used for the development of the sugar spots. Purine base and pyrimidine nucleotide chromatography were carried out in the isopropanol/HCl solvent of Wyatt (1951).

The method of Consden \& Stanier (1952) was employed for the ionophoresis of sugars as borate complexes on Whatman no. 3 MM paper strips; ionophoresis of sugars was carried out also in $0.05 \mathrm{M}$-citrate buffer ( $\mathrm{pH} \mathrm{3.8)}$ on Whatman no. $3 \mathrm{MM}$ paper strips.

Assays of inorganic pyrophosphatase were conducted by the method of Heppel \& Hilmoe (1951).

Assays of organic pyrophosphatase were carried out by allowing a suitable sample of the enzyme to react with UPPG and by measuring the glucose-1phosphate liberated as described previously (Smith \& Mills, 1954). When UPPAG and UPPGA were used as substrates for pyrophosphatase activity, the liberation of uridine-5' - monophosphate (UMP) was determined chromatographically.

Phosphatases acting upon UPPG, UPPAG and UPPGA were detected by the liberation of uridine pyrophosphate (UPP) which was located chromatographically.

Nucleoside triphosphatase activity was measured by allowing a suitable sample of the pneumococcal extract to react either with ATP or with UTP 
followed by measurement of the residual triphosphate as described previously (Smith \& Mills, 1954).

Fractionation of extracts of Streptococcus pneumoniae, strain R19. The packed cocci obtained by centrifugation of a $500 \mathrm{ml}$. culture were suspended in $5 \mathrm{ml} . \mathrm{M} / 15$ phosphate buffer ( $\mathrm{pH} \mathrm{6.6)}$ ) and subjected to disruption in a Mickle disintegrator at $0^{\circ}$ for $30 \mathrm{~min}$. in the presence of two drops of $n$-octanol and an amount of dry ballotini No. 12 equivalent to the volume of packed cocci. Before use, the ballotini were refluxed for $1 \mathrm{hr}$. with $2 \mathrm{~N}-\mathrm{HCl}$, washed with tap water until free from acid, rewashed with several changes of distilled water and dried at $100^{\circ}$. Solid $\left(\mathrm{NH}_{4}\right)_{2} \mathrm{SO}_{4}$ was added to the suspension of disrupted pneumococci to a final concentration of $3 \mathrm{M}$, followed by equilibration at $0^{\circ}$ for $30 \mathrm{~min}$. The precipitate so formed was adsorbed with Standard Super-Cel (Celite 519A, Johns-Manville Corporation) by adding $200 \mathrm{mg}$. Celite/10 ml. solution and allowing the mixture to stand at $0^{\circ}$ for $30 \mathrm{~min}$. before filtration. Filtration was carried out with suction at room temperature and the filter cake eluted for $30 \mathrm{~min}$. by transferring it to $10 \mathrm{ml}$. ice-cold $2 \cdot 5 \mathrm{M}-\left(\mathrm{NH}_{4}\right)_{2} \mathrm{SO}_{4}$. The blended paste was refiltered with suction and subsequent elutions carried out as before with $10 \mathrm{ml}$. volumes of $2.0 \mathrm{M}, 1.5 \mathrm{M}$ and $1.0 \mathrm{M}-\left(\mathrm{NH}_{4}\right)_{2} \mathrm{SO}_{4} ; 10 \mathrm{ml}$. distilled water was used as the final eluting agent. The amount of $\left(\mathrm{NH}_{4}\right)_{2} \mathrm{SO}_{4}$ in each fraction of eluate was adjusted to a final concentration of $3 \mathrm{M}$ with the solid salt, and after equilibration overnight at $0^{\circ}$, the resulting precipitates were collected by centrifugation at $18,000 \mathrm{~g}$ for $30 \mathrm{~min}$. at $0^{\circ}$. Each precipitate was dissolved in the minimum volume of distilled water, dialysed overnight at $0^{\circ}$ and the enzyme solutions so obtained adjusted to a standard volume of $2.5 \mathrm{ml}$. with distilled water and stored at $-12^{\circ}$.

Protein nitrogen was determined by the method described by Mills (1948), the final protein estimation being carried out by the method of Lowry, Rosebrough, Farr \& Randall (1951).

\section{RESULTS}

Enzymes in the unfractionated extracts of Streptococcus pneumoniae, strain R19

The presence of an extremely active DPNH oxidase in $S$. pneumoniae was reported previously (Smith et al. 1958a). Figure 2 indicates the activity of this enzyme in extracts obtained by disruption of strain R19 in a Mickle disintegrator. In this instance, the soluble extract was undialysed and the spectrophotometric assay of the oxidation of DPNH was carried out with the supernatant fluid after centrifugation of the disrupted cocci at $10,000 \mathrm{~g}$ for 20 min. An analogous assay of the oxidation of TPNH (Fig. 2) indicated the presence of an efficient TPNH oxidase.

Inorganic pyrophosphatase, organic pyrophosphatases capable of splitting UPPG, UPPAG and UPPGA to UMP, phosphatases acting on the same uridine pyrophosphoglycosyl compounds to yield UPP and nucleoside triphosphatases utilizing both UTP and ATP as substrates were readily demonstrable in the unfractionated extracts of pneumococci. 
The distribution of various enzymes in fractionated extracts of Streptococcus pneumoniae, strain $\mathbf{R} 19$

The various fractions eluted from Celite with $\left(\mathrm{NH}_{4}\right)_{2} \mathrm{SO}_{4}$ will be referred to in the following manner. Eluates between $3.0 \mathrm{M}$ and $2.5 \mathrm{M}-\left(\mathrm{NH}_{4}\right)_{2} \mathrm{SO}_{4}$ as Fraction $A ; 2.5 \mathrm{M}$ and $2.0 \mathrm{M}-\left(\mathrm{NH}_{4}\right)_{2} \mathrm{SO}_{4}$ as Fraction $B ; 2.0 \mathrm{M}$ and $1.5 \mathrm{M}-$ $\left(\mathrm{NH}_{4}\right)_{2} \mathrm{SO}_{4}$ as Fraction $C ; 1.5 \mathrm{M}$ and $1.0 \mathrm{M}-\left(\mathrm{NH}_{4}\right)_{2} \mathrm{SO}_{4}$ as Fraction D; $1.0 \mathrm{M}-$ $\left(\mathrm{NH}_{4}\right)_{2} \mathrm{SO}_{4}$ and $\mathrm{H}_{2} \mathrm{O}$ as Fraction $E$.

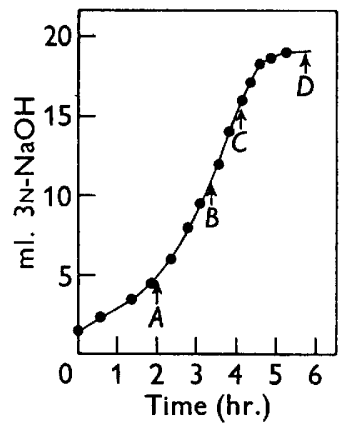

Fig. 1

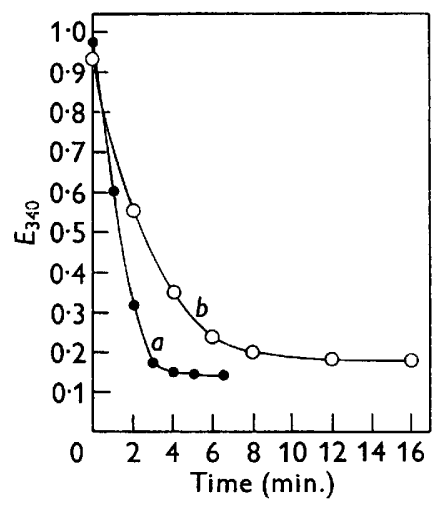

Fig. 2

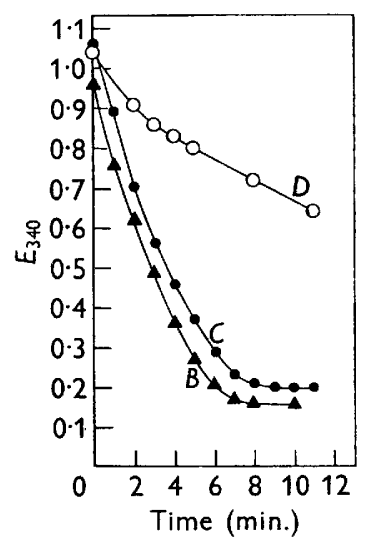

Fig. 3

Fig. 1. Titration with $3 \mathrm{~N}-\mathrm{NaOH}$ of lactic acid liberated by a culture of pneumococcus $\mathbf{R} 19$ following the addition of glucose. The total titration corresponds to an approximate tenfold increase in cell population. Cells were harvested at point $\mathbf{C}$ for the preparation of enzyme extracts and at points $\mathrm{A}, \mathrm{B}, \mathrm{C}$ and $\mathrm{D}$ for analyses of nucleotide content in relation to growth.

Fig. 2. The DPNH and TPNH oxidase activities of an unfractionated extract of cells of pneumococcus $\mathbf{R} 19$ obtained from a $500 \mathrm{ml}$. neutralized culture. The final volume of the extract was $4 \mathrm{ml}$. Curve $(a): 25 \mu \mathrm{l}$. extract incubated with $0 \cdot 13 \mu$ mole DPNH and 0.1 M-TRIS buffer, pH 7.8, to $1.0 \mathrm{ml}$. Curve $(b): 30 \mu$ l. extract incubated with $0 \cdot 12 \mu$ mole TPNH and $0.1 \mathrm{~m}$-tris buffer, pH $7 \cdot 8$, to $1.0 \mathrm{ml}$.

Fig. 3. DPNH oxidase activity of fractions $\mathrm{B}, \mathrm{C}$ and $\mathrm{D}$ obtained by Celite-( $\left.\mathrm{NH}_{4}\right)_{2} \mathrm{SO}_{4}$ fractionation of disintegrated pneumococcal cells. $100 \mu \mathrm{l}$. extract incubated with $0.13 \mu$ mole DPNH and 0.1 M-tris buffer, $\mathrm{pH} 7.8$ to $1.0 \mathrm{ml}$. Fractions $\mathrm{A}$ and $\mathrm{E}$ were inactive in this system.

DPNH and TPNH oxidases. It can be seen from Fig. 3 that the DPNH oxidase was located almost entirely in Fractions B and C. This distribution was consistent in several fractionations although slight activity was demonstrable occasionally in Fraction D. Fractions A and E were completely devoid of oxidase activity. While an active TPNH oxidase is present in the unfractionated extract of strain $\mathrm{R} 19$, none of the $\left(\mathrm{NH}_{4}\right)_{2} \mathrm{SO}_{4}$ fractions assayed acted upon TPNH either in the presence of or in the absence of DPNH. It would appear, therefore, that the oxidase in the fractions studied is specific for DPNH.

Inorganic pyrophosphatase, organic pyrophosphatases, phosphatases and nucleoside triphosphatases. Unfractionated extracts were rich in all these 
enzymes as was the total material precipitated with $\mathbf{3} \mathrm{M}-\left(\mathrm{NH}_{4}\right)_{2} \mathrm{SO}_{4}$. When Celite was used as the adsorbing agent under the conditions specified, however, inorganic pyrophosphatase, organic pyrophosphatases and phosphatases were retained by the Celite in the majority of fractionations and the $\left(\mathrm{NH}_{4}\right)_{2} \mathrm{SO}_{4}$ Fractions A, B, C, D and E were substantially free from these enzymes. Nucleoside triphosphatases utilizing both ATP and UTP as substrates appeared, however, in all fractions.

Uridyl transferases. Uridyl transferase activity was measured by the incorporation of ${ }^{32} \mathrm{P}$ labelled inorganic pyrophosphate $(\mathbf{P}-\mathbf{P})$ in accordance with the following reactions:

$$
\begin{aligned}
& \text { UPPG }+{ }^{32} \mathbf{P} \_{ }^{32} \mathbf{P} \rightleftarrows \mathrm{UP}^{32} \mathbf{P}^{32} \mathbf{P}+\text { glucose-1-phosphate } \\
& \text { UPPAG }+{ }^{32} \mathbf{P} \_{ }^{32} \mathbf{P} \rightleftarrows \mathbf{U P}^{32} \mathbf{P}^{32} \mathbf{P}+\text { acetylglucosamine-1-phosphate }
\end{aligned}
$$

The method of assay was essentially that of Dr A. Munch-Petersen (personal communication, 1957) based upon that of Berg (1956). The nucleotides were adsorbed on pyrophosphate-washed Norite, washed with water and eluted with $50 \%(\mathrm{v} / \mathrm{v})$ ethanol in water. For counting, a suitable sample of the Norite + aqueous ethanol suspension was plated. As further confirmatory evidence of uridyl transferase activity, the residual aqueous ethanol eluate was evaporated to a convenient volume and chromatographed in the neutral ethanol/ammonium acetate solvent of Paladini \& Leloir (1952). In all instances in which the Norite + aqueous ethanol suspension showed isotopic activity greater than that of the control experiment, chromatography showed such activity to be localized entirely in UTP or UPP, the latter being derived from UTP by nucleoside triphosphatase activity.

In all experiments, chromatographically pure UPPG and UPPAG were used, care being taken to ensure that the former compound was free from UPPgalactose (Mills, Smith \& Lochhead, 1957).

Typical values for the uridyl transferase activities of unfractionated extracts are shown in Table 1. It will be seen that the pyrophosphorolytic activity of such extracts is very similar when either UPPG or UPPAG is provided as the substrate. When an enzyme fraction eluted from the Celite filter cake between 3.0 $\mathrm{M}$ and 1.0 M- $\left(\mathrm{NH}_{4}\right)_{2} \mathrm{SO}_{4}$ was used, however, pyrophosphorolytic activity was more pronounced when UPPAG was used as the substrate. The results suggest that the uridyl transferases acting upon UPPG and UPPAG may be separable entities and attempts were made to fractionate the enzymes by means of the Celite $/\left(\mathrm{NH}_{4}\right)_{2} \mathrm{SO}_{4}$ technique described. Enzyme Fractions A, B, $\mathrm{C}$ and $\mathrm{D}$ were shown to have pyrophosphorolytic activity towards UPPG which activity could not be dissociated completely from the pyrophosphorolysis of UPPAG. Fraction E, however, showed specific pyrophosphorolytic activity towards UPPAG. The results are shown in Table 1.

Figure 4 shows the pyrophosphorolysis of UPPG by Fraction $\mathbf{B}$ and of UPPAG by Fraction D; the results are expressed as an ultraviolet absorption scan $(260 \mathrm{~m} \mu)$ of the chromatographed material. It will be seen that both Fractions B and D possessed considerable nucleoside triphosphatase activity towards UTP giving rise to uridine pyrophosphate (UPP) and UMP. 
Table 1. Pyrophosphorolysis of UPPG and UPPAG by whole and by fractionated extracts of Streptococcus pneumoniae, strain $\mathbf{R} 19$

Chromatographically pure UPPG and UPPAG were used as substrates. $0 \cdot 6 \mu$ mole of the requisite nucleotide was incubated with $1 \mu \mathrm{mole} \mathrm{MgCl}_{2}, 4 \mu \mathrm{mole}$ inorganic pyrophosphate labelled with ${ }^{22} \mathrm{P}(2 \mu \mathrm{c}), 100 \mu \mathrm{l}$. of the fraction indicated and $0.1 \mathrm{M}$-tris buffer, $\mathrm{pH} 7.8$ to $1.0 \mathrm{ml}$., for $30 \mathrm{~min}$. at room temperature. Controls run with no addition of nucleotide. The reaction mixtures were treated with perchloric acid (final concentration $1 \%, w / v$ ) and protein removed by centrifugation. Nucleotides were adsorbed on pyrophosphate washed charcoal (15 mg. per $\mu$ mole nucleotide) for $10 \mathrm{~min}$., the charcoal separated by centrifugation, washed twice with water and suspended in $1 \mathrm{ml} .50 \%$ ethanol containing one drop of $5 \% \mathrm{NH}_{4} \mathrm{OH}$. $100 \mu \mathrm{l}$. of each suspension was plated, dried and the radioactivity determined with an end window counter. Results expressed as counts per minute (test minus control).

\begin{tabular}{|c|c|c|}
\hline \multirow[b]{2}{*}{ Fraction } & \multicolumn{2}{|c|}{ Substrate } \\
\hline & $\begin{array}{c}\text { UPPG } \\
\text { (c./min.) }\end{array}$ & $\begin{array}{l}\text { UPPAG } \\
\text { (c./min.) }\end{array}$ \\
\hline $\begin{array}{l}\text { Unfractionated } \mathrm{R} 19 \text { extract } \\
3 \cdot 0-1 \cdot 0 \mathrm{M}-\left(\mathrm{NH}_{4}\right)_{2} \mathrm{SO}_{4} \text { fraction (fractions } \mathrm{A}-\mathrm{D} \text { inclusive) } \\
\left.1 \cdot 0 \mathrm{M}-\left(\mathrm{NH}_{4}\right)_{2} \mathrm{SO}_{4} \text { to water (fraction } \mathrm{E}\right)\end{array}$ & $\begin{array}{r}18,000 \\
4,000 \\
0\end{array}$ & $\begin{array}{r}16,000 \\
16,700 \\
6,000\end{array}$ \\
\hline
\end{tabular}

\section{Metabolism of galactose and mannose}

Because of the occurrence of galactose and mannose in the cellular polysaccharide of Streptococcus pneumoniae strain R19 (Smith, Mills, Harper \& Galloway, $1957 b$ ), and because of the known ability of pneumococci to utilize both these sugars, experiments were carried out to determine the nature of the enzyme systems involved in the utilization of these two hexoses. Smith et al. (1957a, b), Glaser (1957), Glaser \& Brown (1957), and Markovitz, Cifonelli \& Dorfman (1958) have implicated uridine pyrophosphoglycosyl compounds in polysaccharide synthesis. It was considered desirable, therefore, to determine whether or not UPPgalactose and GPPM were pyrophosphorylysed by extracts of the organism under study.

UPPgalactose was isolated from a preparation of yeast containing both UPPG and UPPgalactose (Mills, Smith \& Lochhead, 1957) by oxidizing the UPPG to UPPGA followed by separation of the residual UPPgalactose by chromatography. In experiments with such chromatographically pure UPPgalactose and with GPPM, no evidence was obtained for the formation of $\mathrm{UP}^{32} \mathrm{P}^{32} \mathrm{P}$ or $\mathrm{GP}^{32} \mathrm{P}^{32} \mathrm{P}$ respectively either by whole or by fractionated extracts of Streptococcus pneumoniae, strain R19.

The utilization of galactose by micro-organisms and mammalian tissues has been shown to follow the pathway of reactions outlined below (cf. Kalckar \& Maxwell, 1958).

$$
\begin{aligned}
& \text { Galactose }+ \text { ATP } \rightarrow \text { galactose-1-phosphate + ADP (galactokinase) } \\
& \text { Galactose-1-phosphate + UPPG } \rightleftarrows \text { Glucose-1-phosphate + UPPgalactose } \\
& \text { (phosphogalactosyl uridyl transferase) }
\end{aligned}
$$

The presence of the enzyme phosphogalactosyl uridyl transferase in the 3.0 M-1.0 M- $\left(\mathrm{NH}_{4}\right)_{2} \mathrm{SO}_{4}$ fraction is demonstrated clearly by the results presented 
in Fig. 5. From the data shown in Fig. 5, it is apparent that the presence of UPPG was necessary for the conversion of galactose-1-phosphate to glucose-1phosphate; the latter was further converted to glucose-6-phosphate and subsequently oxidized to 6-phosphogluconic acid by the TPN-linked glucose-6phosphate dehydrogenase of the pneumococci.

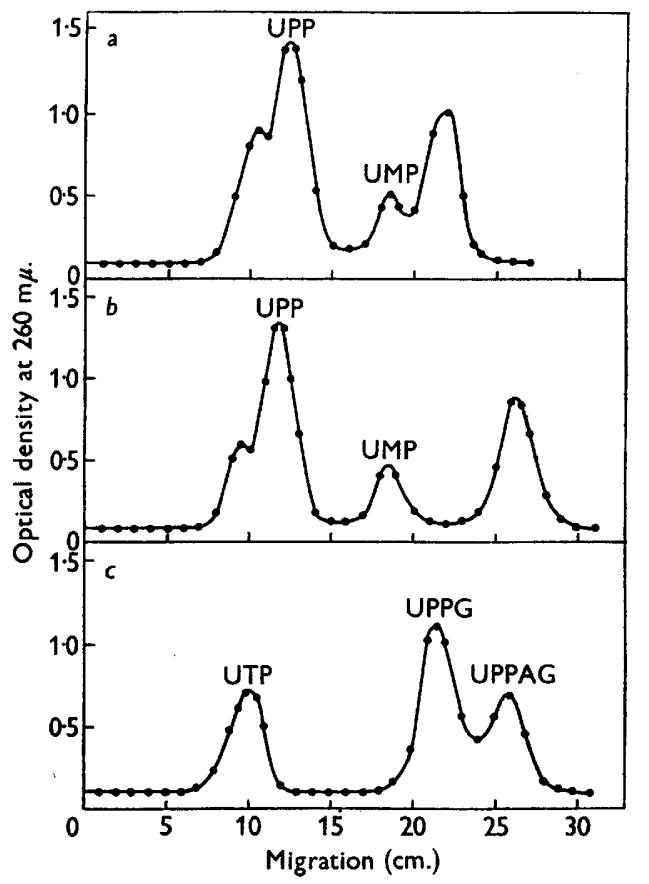

Fig. 4

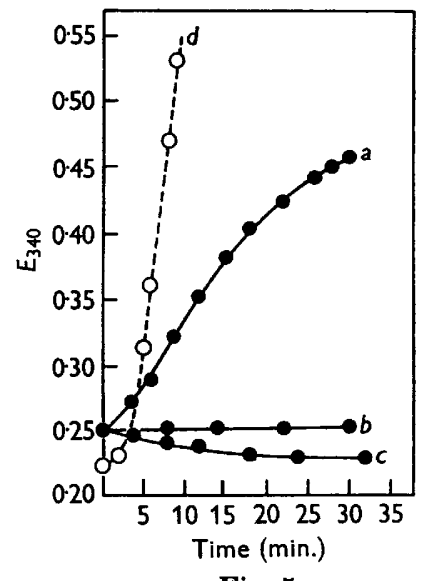

Fig. 5

Fig. 4. The pyrophosphorolysis of UPPG and UPPAG by ammonium sulphate fractions of an extract of $S$. pneumoniae, strain R 19. Experimental details as in Table 1 . The ethanol eluate from the charcoal was concentrated and chromatographed in the ethanol-ammonium acetate solvent, $\mathrm{pH}$ 7.5. The chromatograms were scanned in the Unicam S.P. 500 spectrophotometer at $260 \mathrm{~m} \mu$ (cf. Smith \& Mills, 1954). (a) UPPG and fraction B; (b) UPPAG and fraction D; (c) pure marker substances chromatographed simultaneously with $(a)$ and $(b)$.

Fig. 5. The phosphogalactosyl uridyl transferase activity of an ammonium sulphate fraction of an extract of $S$. pneumoniae, strain R 19. (a) Complete system consisting of $0 \cdot 1 \mu \mathrm{mole}$ UPPG, 0.2 $\mu$ mole $\alpha$-galactose-1-phosphate, $0.25 \mu$ mole TPN, $5 \mu$ mole $\mathrm{MgCl}_{2}, 2.5 \mu \mathrm{mole}$ cysteine, $100 \mu \mathrm{l}$. of a $3 \cdot 0 \mathrm{M}-1 \cdot 0 \mathrm{M}-\left(\mathrm{NH}_{4}\right)_{2} \mathrm{SO}_{4}$ eluate fraction of $\mathrm{R} 19$ cells and $0 \cdot 1 \mathrm{M}$-tris buffer, pH 7.8, to $1 \cdot 0 \mathrm{ml}$; (b) complete system without UPPG; (c) complete system without $\alpha$-galactose-1-phosphate; $(d)$ same system but with $0.2 \mu$ mole $\alpha$-glucose-1phosphate in place of UPPG and $\alpha$-galactose-1-phosphate.

The presence of UPPgalactose-4-epimerase in the extracts of strain R19 was demonstrated as follows. ${ }^{14} \mathrm{C}$-labelled UPPG was incubated with the $3.0 \mathrm{M}-1 \cdot 0 \mathrm{M}-\left(\mathrm{NH}_{4}\right)_{2} \mathrm{SO}_{4}$ fraction in the presence of a small amount of DPN, followed by separation of the nucleotides by adsorption on charcoal, elution and chromatography in ethanol/ammonium acetate. The chromatographic area corresponding to UPPG was eluted, the sugars liberated by acid hydrolysis 
and identified by ionophoresis in borate buffer at $\mathrm{pH} \mathbf{8 \cdot 6}$. The positions of the sugar spots were located by the aniline hydrogen phthalate reagent and by autoradiography. In all such experiments glucose and galactose were identified and, in addition, a third radioactive reducing substance was invariably evident. This substance migrated in borate buffer to the same area as mannose. On chromatography in butanol/acetic acid/water, however, this substance did not occupy the position of mannose but had an $\mathbf{R}_{\text {glucose }}$ value of $\mathbf{0 \cdot 3 0}$ (mannose: $\mathbf{R}_{\text {glucose }}=\mathbf{1 \cdot 2 5}$ ). At present the identity of this material is unknown.

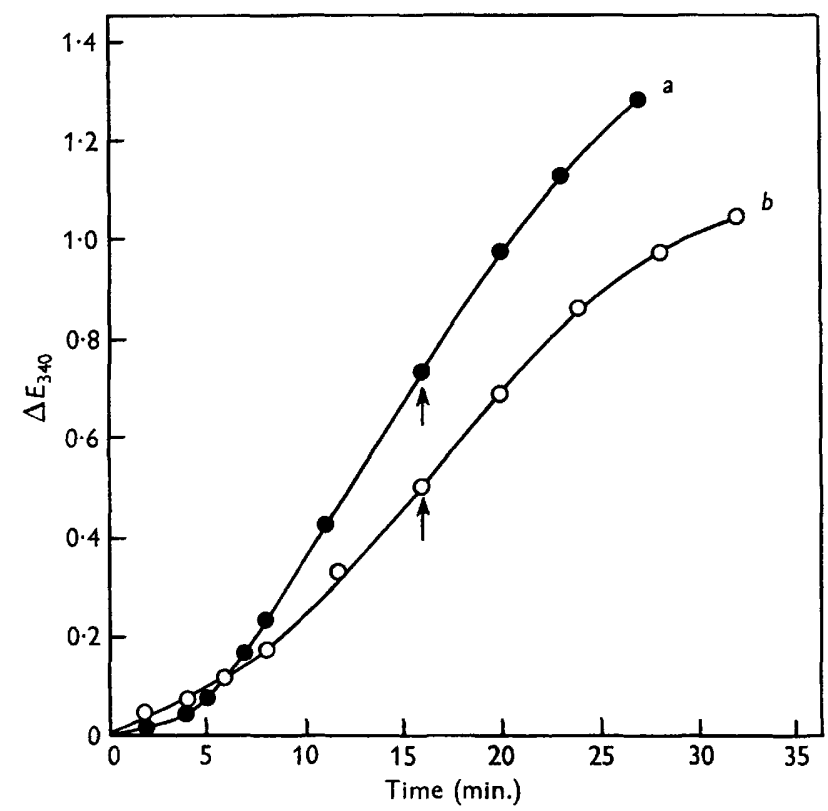

Fig. 6. The conversion of mannose and of mannose-1-phosphate to 6-phosphogluconic acid by an ammonium sulphate fraction of an extract of $S$. pneumoniae, strain $R 19$. (a) 0.4 $\mu$ mole mannose, 1.0 $\mu$ mole ATP, $0.25 \mu$ mole TPN, $5 \mu$ mole $\mathrm{MgCl}_{2}, 2.5 \mu$ mole cysteine, $100 \mu \mathrm{l}$. of a $3.0 \mathrm{M}-1.0 \mathrm{M}-\left(\mathrm{NH}_{4}\right)_{2} \mathrm{SO}_{4}$ fraction of an extract of $\mathrm{R} 19$ and $0.1 \mathrm{M}-$ TRIS buffer, $\mathrm{pH} \mathrm{7.8}$, to $1.0 \mathrm{ml}$. (b) As in (a) but with $0.2 \mu$ mole mannose-1-phosphate in place of mannose and ATP. $\Delta E_{340}$ values corrected for blanks run in the absence of mannose in $(a)$ and mannose-1-phosphate in $(b)$. $0.1 \mu$ mole UPPG was added at the points indicated by the arrows.

To date, it has not proved possible to demonstrate the presence of galactokinase in the extracts of strain R 19 by means of spectrophotometric techniques.

Figure 6 shows the results of experiments on the conversion of mannose and of mannose-1-phosphate (M-1-P) to glucose phosphate with subsequent oxidation to 6-phosphogluconic acid. These reactions proceeded in the absence of added UPPG, and the addition of UPPG did not accelerate the reactions.

Berger, Slein, Colowick \& Cori (1946) and Slein, Cori \& Cori (1950) showed that mannose is phosphorylated by ATP in the presence of yeast and of mammalian hexokinase to give mannose-6-phosphate (M-6-P), and Slein $(1950,1954)$ described the conversion of M-6-P to glucose-6-phosphate, via 
fructose-6-phosphate. It would appear probable that this pathway is operative in Streptococcus pneumoniae, strain R 19. LeLoir (1951) has shown that M-1-P is converted to M-6-P by phosphoglucomutase, a mechanism which may be operative in the present case.

\section{The formation of UPPGA by fractionated extracts of Streptococcus pneumoniae strain $\mathbf{R} 19$}

The inability to demonstrate spectrophotometrically the conversion : of UPPG to UPPGA by extracts of $S$. pneumoniae, strain R 19, results from the presence of DPNH oxidase (Smith et al. 1958a). In addition, it is not feasible to follow this reaction spectrophotometrically in fractionated extracts of strain R19 because the distribution of the DPNH oxidase during such fractionation follows the separation pattern of the enzyme which converts UPPG to UPPGA.

Smith et al. (1958a) demonstrated the formation of UPPGA from UPPG by a pneumococcal enzyme system which required the presence of DPN and, in this instance, the isolation and identification of the UPPGA was carried out by paper chromatographic techniques. The present experiment describes the isolation and identification of UPPGA by means of ion-exchange techniques.

Six $\mu$ mole chromatographically pure UPPG were incubated with $5 \mathrm{ml}$. 0.1 M-tris (2-amino-2-hydroxymethyl-propane-1 :3-diol) buffer (pH 9.0), $1 \mathrm{ml}$. 3.0 M-1.0M- $\left(\mathrm{NH}_{4}\right)_{2} \mathrm{SO}_{4}$ fraction and $12 \mu$ moles $\mathrm{DPN}$ for $30 \mathrm{~min}$. at room temperature. At the end of this period the reaction was stopped by the addition of $10 \%(\mathrm{w} / \mathrm{v})$ perchloric acid to a final concentration of $1 \%(\mathrm{w} / \mathrm{v})$ and protein was removed by centrifugation at $4^{\circ}$. DPN and DPNH were removed from the deproteinized solution by passing it through a Dowex $50 \mathrm{H}^{+}$column as described by Smith \& Mills (1954) for the removal of AMP. The complete removal of DPN and DPNH was checked by spectrophotometric assay of the column effluent (Racker, 1950). The column effluent was adjusted to $\mathrm{pH} 9$ with dilute $\mathrm{NH}_{4} \mathrm{OH}$ and applied to a Dowex $1 \mathrm{Cl}^{\prime}$ column $\left(11 \mathrm{~cm} . \times 1 \mathrm{~cm}^{2}\right)$. Figure 7 indicates the results obtained by elution of the column with increasing concentrations of $\mathrm{HCl}$ and $\mathrm{NaCl}$.

The materials eluted from the Dowex $1 \mathrm{Cl}^{\prime}$ column were adsorbed on charcoal, eluted with ethanol and chromatographed in the ethanol/ammonium acetate solvent at $\mathrm{pH} 7$. The material eluted in the $0.01 \mathrm{~N}-\mathrm{HCl} / 0.01 \mathrm{M}-\mathrm{NaCl}$ was mainly uridylic acid (UMP-5'). The component eluted in $0.01 \mathrm{~N}-\mathrm{HCl} / \mathbf{0} \cdot 03 \mathrm{M}-$ $\mathrm{NaCl}$ chromatographed as UPPG. Hydrolysis of the chromatographic band corresponding to UPPG with $0.01 \mathrm{~N}-\mathrm{HCl}$ for $15 \mathrm{~min}$. showed the presence of UPP; the reducing components liberated by hydrolysis were three in number as determined by ionophoresis in borate buffer and chromatography in butanol/acetic acid/water. These components were identified as glucose, galactose and the unknown material referred to above. The component eluted from the column by $0 \cdot 01 \mathrm{~N}-\mathrm{HCl} / 0.05 \mathrm{M}-\mathrm{NaCl}$ was identified as UPPGA (Smith \& Mills, 1954; Smith et al. 1957a; Smith et al. 1958a). The only uronic acid present was glucuronic acid. This fact, and the observation that when pure UPPGA was incubated with a $3 \cdot 0 \mathrm{M}-1 \cdot 0 \mathrm{M}-\left(\mathrm{NH}_{4}\right)_{2} \mathrm{SO}_{4}$ fraction there was 
no formation of UPPgalacturonic acid, indicates that Streptococcus pneumoniae strain R19 does not contain the UPPuronic acid-4-epimerase found in the capsulated type I strain studied by Smith, Mills, Bernheimer \& Austrian $(1958 b)$.

It will be seen in Fig. 7 that the extent of conversion of UPPG to UPPGA was small; this observation, coupled with the marked instability of the UPPG dehydrogenase in the extracts used, suggested that there may have been considerable inactivation of the enzyme during preparation. It is well known

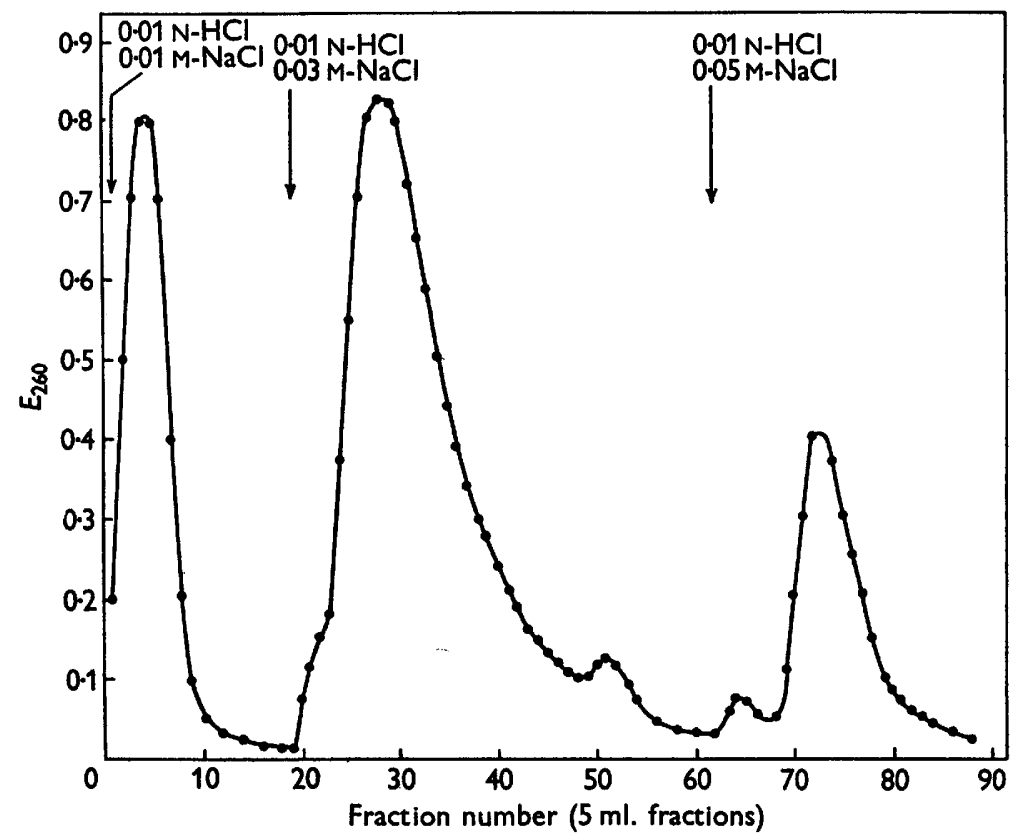

Fig. 7. Dowex $1 \mathrm{Cl}^{\prime}$ column elution diagram showing the formation of UPPGA from UPPG by an ammonium sulphate fraction of an extract of $S$. pneumoniae, strain $R 19$. See text for experimental details.

that pneumococci actively produce hydrogen peroxide (McLeod \& Gordon, 1922; cf. the presence of an active DPNH oxidase and the absence of the cytochrome system) and it was considered that this substance may be the inactivating agent. Preliminary experiments in which catalase was present throughout the procedures of fractionation and dialysis have shown increased yields of UPPGA. Further investigation of this problem is in progress.

\section{Stability of the enzyme fractions}

The enzyme preparations obtained by $\left(\mathrm{NH}_{4}\right)_{2} \mathrm{SO}_{4}$ fractionation were most stable when stored at $-12^{\circ}$. Under such circumstances, however, the DPNH oxidase lost $90 \%$ of its original activity over a period of 2 weeks; uridyl transferase activity showed a decrease of $30 \%$ after 1 week. The least stable of the uridine pyrophosphoglycosyl enzyme systems under these conditions was the UPPG dehydrogenase which showed complete loss of activity within 2 days. 
Nucleotide analysis at various stages of growth

Four identical $500 \mathrm{ml}$. cultures of the strain R19 were incubated for $16 \mathrm{hr}$. at which time there were $c .10^{9} \mathrm{cocci} / \mathrm{ml}$. (by turbidimetry). Glucose was then added and the lactic acid formed during subsequent incubation was neutralized in the manner described. Growth was stopped at the four points indicated in Fig. 1, the number of cocci $/ \mathrm{ml}$. determined and a nucleotide analysis carried out on Dowex $\mathbf{~ C l}^{\prime}$ as described for Fig. 7, the nucleotides present in each fraction being identified by paper chromatography. The results are presented in Table 2.

Table 2. Nucleotide analysis of Streptococcus pneumoniae, strain $\mathbf{R} 19$, at various stages of growth

Total density units (D.U.) $=E_{260} \times$ volume.

\begin{tabular}{|c|c|c|c|c|c|c|}
\hline \multirow[b]{2}{*}{$\begin{array}{c}\text { Phase of } \\
\text { growth } \\
\text { (cf. Fig. 1) }\end{array}$} & \multicolumn{4}{|c|}{$\begin{array}{c}0.01 \mathrm{~N}-\mathrm{HCl} \\
0.03 \mathrm{M}-\mathrm{NaCl} \\
\text { Eluate }\end{array}$} & \multirow[b]{2}{*}{$\begin{array}{c}\text { 0.01 } \mathrm{N}-\mathrm{HCl}, \\
\text { 0.05 } \mathrm{M}-\mathrm{NaCl} \\
\text { Eluate } \\
\text { Total D.U. }\end{array}$} & \multirow[b]{2}{*}{$\begin{array}{c}0.01 \mathrm{~N}-\mathrm{HCl}, \\
0.20 \mathrm{M}-\mathrm{NaCl} \\
\text { Eluate } \\
\text { Total D.u. }\end{array}$} \\
\hline & Cells/ml. & $\begin{array}{c}0.01 \mathrm{~N}-\mathrm{HCl}, \\
0.01 \mathrm{M}-\mathrm{NaCl} \\
\text { Eluate } \\
\text { Total v.u. }\end{array}$ & Total D.U. & $\begin{array}{l}\text { Ratio: } \\
\text { UPPG } \\
\text { UPPAG }\end{array}$ & & \\
\hline $\mathbf{A}$ & $1.5 \times 10^{9}$ & 76 & 20 & 0.20 & 17 & 15 \\
\hline $\mathbf{B}$ & $3.1 \times 10^{9}$ & 122 & 59 & 0.42 & 19 & 8 \\
\hline $\mathbf{C}$ & $6.3 \times 10^{9}$ & 176 & 83 & $1 \cdot 84$ & 6 & 7 \\
\hline D & $10.0 \times 10^{9}$ & 400 & 188 & $1 \cdot 30$ & 43 & 88 \\
\hline
\end{tabular}

A number of points emerge from these analyses. It will be noted that, in the $0.01 \mathrm{~N}-\mathrm{HCl} / 0.03 \mathrm{M}-\mathrm{NaCl}$ fraction, the UPPG/UPPAG ratio increased markedly up to point $\mathrm{C}$ and then fell slightly at point $\mathrm{D}$. In the $0.01 \mathrm{~N}-\mathrm{HCl} /$ $0.05 \mathrm{M}-\mathrm{NaCl}$ and $0.01 \mathrm{~N}-\mathrm{HCl} / 0.2 \mathrm{M}-\mathrm{NaCl}$ fractions, there was no significant alteration in the nucleotide content until the resting phase $\mathbf{D}$ was reached; at this point the material accumulating in the $0.01 \mathrm{~N}-\mathrm{HCl} / 0.05 \mathrm{M}-\mathrm{NaCl}$ fraction was UPPGA and in the $0.01 \mathrm{~N}-\mathrm{HCl} / 0.20 \mathrm{M}-\mathrm{NaCl}$ fraction, the triphosphates UTP and ATP.

\section{DISCUSSION}

The preparation of extracts of pneumococci by their disruption in a Mickle disintegrator in the presence of $n$-octanol has made possible the identification and partial purification of a number of enzymes of Streptococcus pneumoniae, strain R19, which are concerned with uridine pyrophosphoglycosyl metabolism. From these and from other experiments, the pathways for the formation of UPPG and UPPgalactose have been established. The difficulties encountered in establishing the mechanism of formation of UPPGA in S. pneumoniae, strain $\mathbf{R} 19$, have resulted from the presence within this organism of a DPNH oxidase which does not permit the use of spectrophotometric assays. Also, very active organic pyrophosphatases and phosphatases in unfractionated extracts of strain $\mathrm{R} 19$ have caused a rapid breakdown of uridine pyrophosphoglycosyl substrates during attempts to follow the metabolism of these com- 
pounds. While direct fractionation of pneumococcal extracts with $\left(\mathrm{NH}_{4}\right)_{2} \mathrm{SO}_{4}$ does not alter the problem of the breakdown of such substrates, the use initially of Celite as an adsorbing agent under the conditions specified results in the almost complete elimination of interfering organic pyrophosphatases and phosphatases.

The conversion of UPPG to UPPGA by fractionated extracts of strain R 19 is mediated through a $\mathrm{DPN}^{+}$linked system; in the absence of $\mathrm{DPN}^{+}$no formation of the uronic acid nucleotide from UPPG was observed. In view of the DPN+-dependent pathway for the formation of UPPGA from UPPG established by Strominger, Kalckar, Axelrod \& Maxwell (1954) and Strominger, Maxwell, Axelrod \& Kalckar (1957) for liver tissue, it would appear that an analogous system is operative in the metabolism of the pneumococci used in the present work. The existence of an extremely active DPNH oxidase can be understood as having considerable importance in pneumococcal metabolism during UPPGA synthesis by providing a rapid cyclic method of replenishing DPN+ from DPNH.

From the data presented, it appears that the uridyl transferases which utilize UPPG and UPPAG as substrates may be separable entities. The inability of strain R19 to pyrophosphorolyse GPPM suggests that mannose or a compound containing mannose may function as recipient during the synthesis of the cellular polysaccharide of the organism, the 'active transferable' sugar being derived either from UPPAG or from UPPgalactose.

It has been shown in the present work that mannose can be converted to glucose phosphate by extracts of Streptococcus pneumoniae, strain R19, without the participation of UPPG, whereas UPPG is essential for the conversion of galactose-1-phosphate to glucose-1-phosphate via the phosphogalactosyl uridyl transferase system. The direct formation of UPPgalactose from galactose-1-phosphate and UTP does not appear to be operative in this strain of pneumococcus.

The formation of glucuronic acid in Streptococcus pneumoniae, strain $\mathbf{R} 19$, appears to follow the pathway identified in animal tissues (cf. Mills, Lochhead \& Smith, 1958) which includes the nucleotides UPPG and UPPGA. It is interesting to note that, although strain R19 does not produce capsular polysaccharide, there seems to be little or no impairment of the synthesis of glucuronic acid. It is likely, therefore, that the inability of strain R19 to form a capsule results from a mutation which affects the formation of rhamnose and/or one concerned with the polymerization of capsular polysaccharide. Rhamnose constitutes approximately $50 \%$ of type II capsular material; at present nothing is known concerning the synthesis of this methylpentose by pneumococci.

The results of the nucleotide analyses at various stages of growth show an increase in UPPG during the logarithmic phase followed by a decrease during the resting phase. The increased production of UPPG may be related to the necessity for the formation of UPPgalactose, the latter participating presumably in the synthesis of somatic $\mathrm{C}$ polysaccharide. A knowledge of the ratio of UPPG/UPPgalactose at this stage would elucidate this point more thoroughly. 
The decrease in UPPG at the end of growth may be coupled with the increase of UPPglucuronic acid at this point. The appearance of UPPGA at this stage only, may indicate that, in the absence of the production of capsular polysaccharide, the synthesis of UPPGA is relegated to that of a minor pathway during the growth of this strain. The accumulation of triphosphates at the end of growth may be related to the decreased rate of formation of UPPglycosyl compounds when growth ceases.

The preliminary experiments on the effect of catalase on UPPG dehydrogenase activity suggest inactivation of this enzyme by $\mathrm{H}_{2} \mathrm{O}_{2}$. The ability of sulphydryl compounds and of proteins to replace catalase is being investigated to ascertain the nature of this protective process.

One of us (E.E.B.S.) is the holder of a Senior Research Award of the Carnegie Institution of Washington. This investigation was supported in part by a grant from the Medical Research Council, by the Rankin Fund of the University of Glasgow, by research grant E-1018 (C2) from the Institute of Allergy and Infectious Diseases, United States Public Health Service, and by a travel grant from Lederle Laboratories Division, American Cyanamide Co. The authors wish to thank Mr Brian Galloway for valuable technical assistance.

\section{REFERENCES}

Berg, P. (1956). Acyl adenylates: an enzymatic mechanism of acetate activation. J. biol. Chem. 222, 991.

Berger, L., Slein, M. W., Colowick, S. P. \& Cori, C. F. (1946). Isolation of hexokinase from baker's yeast. J. gen. Physiol. 29, 379.

Bernheimer, A. W. (1953). Synthesis of Type III pneumococcal polysaccharide by suspensions of resting cells. J. exp. Med. 97, 591.

Butler, K. \& Stacey, M. (1955). Immunopolysaccharides. Part IV. Structural studies on the Type II Pneumococcus specific polysaccharide. J. chem. Soc. p. 1537.

Cabib, E. \& LeLoir, L. F. (1954). Guanosine diphosphate mannose. J. biol. Chem. $206,779$.

Caputto, R., Lelorr, L. F., Cardini, C. E. \& Paladini, A. C. (1950). Isolation of the coenzyme of the galactose phosphate-glucose phosphate transformation. J. biol. Chem. 184, 333.

CoLowick, S. P. (1938). Synthetic mannose-1-phosphoric acid and galactose-1phosphoric acid. J. biol. Chem. 124, 557.

Consden, R. \& Stanier, W. M. (1952). Ionophoresis of sugars on paper and some applications to the analysis of protein polysaccharide complexes. Nature, Lond. $169,783$.

GrASER, L. (1957). Enzymatic synthesis of cellulose by Acetobacter xylinum. Biochim. Biophys. Acta, 25, 436.

Glaser, L. \& Brown, D. H. (1957). The synthesis of chitin in cell-free extracts of Neurospora crassa. J. biol. Chem. 228, 729.

Green, A. A. \& Cori, G. T. (1943). Crystalline muscle phosphorylase. J. biol. Chem. 151, 21.

Heppel, L. A. \& Hilmoe, R. J. (1951). Purification of yeast inorganic pyrophosphatase. J. biol. Chem. 192, 87.

Heppel, L. A. \& Hilmoe, R. J. (1955). Inorganic pyrophosphatase. Biochem. Prep. 4, 34.

JÜRGENS, A. (1937). Investigations regarding the fermentative ability of the Pneumococci. Acta path. microbiol. scand. 14, 511. 
Kalckar, H. M. \& Maxwell, E. S. (1958). Biosynthesis and metabolic function of uridine diphosphoglucose in mammalian organisms and its relevance to certain inborn errors. Physiol. Rev. 38, 77.

Langvad-Nielsen, A. (1944). Fermentation power of pneumococci. Acta path. microbiol. scand. $21,370$.

LeLoIn, L. F. (1951). The metabolism of hexosephosphates: in $A$ Symposium on Phosphorus Metabolism, 1, 67. Ed. McElroy, W. D. \& Glass, B. Baltimore: Johns Hopkins Press.

Lowry, O. H., Rosebrough, N. J., Farr, A. L. \& Randall, R. J. (1951). Protein measurement with the Folin phenol reagent. J. biol. Chem. 193, 265.

McCready, R. M. \& Hassid, W. Z. (1955). $\alpha$-D-Glucose-1-phosphate. Biochem. Prep. 4, 63.

MacLeod, C. M. \& KRaUss, M. R. (1947). Stepwise intratype transformation of pneumococcus from $R$ to $S$ by way of a variant intermediate in capsular polysaccharide production. J. exp. Med. 86, 439.

McLeod, J. W. \& Gordon, J. (1922). Production of hydrogen peroxide by bacteria. Biochem. J. 16, 499.

Markovitz, A., Cifonelu, J. A. \& Dorfman, A. (1958). Biosynthesis of hyaluronic acid by cell-free extracts of group-A streptococci. Biochim. biophys. Acta, 28, 453.

MrLus, G. T. (1948). The $\beta$-glucuronidase activity of ox spleen and the assay of $\beta$-glucuronidase preparations. Biochem. $J .43,125$.

Milis, G. T., Lochread, A. C. \& SMirh, E. E. B. (1958). Uridine pyrophosphoglycosyl compounds and the formation of glucuronides by isolated enzyme systems. Biochim. biophys. Acta, 27, 103.

Milis, G. T., Smith, E. E. B. \& Lochread, A. C. (1957). Presence of uridine pyrophosphogalactose and uridine pyrophosphogalactose-4-epimerase in nongalactose adapted yeasts. Biochim. biophys. Acta, 25, 521.

Munch-Petersen, A. (1955). Investigations of the properties and mechanism of the uridine diphosphate glucose pyrophosphorylase reaction. Acta chem. scand. 9, 1523.

Munch-Petersen, A., Kalckar, H. M., Cutolo, E. \& Smith, E. E. B. (1953). Enzymic production of uridine triphosphate: Uridine diphosphoglucose pyrophosphorolysis. Nature, Lond. 172, 1036.

Paradini, A. C. \& Lelorr, L. F. (1952). Studies on uridine-diphosphate-glucose. Biochem. J. 51, 426.

Partridge, S. M. (1948). Filter paper partition chromatography of sugars. Biochem. J. 42, 238.

Partridge, S. M. (1949). Aniline hydrogen phthalate as a spraying reagent for chromatography of sugars. Nature, Lond. 164, 443.

RACKER, E. (1950). Crystalline alcohol dehydrogenase from bakers' yeast. J. biol. Chem. 184, 313.

Srern, M. W. (1950). Phosphomannose isomerase, J. biol. Chem. 186, 753.

Sirin, M. W. (1954). Phosphohexose isomerases. Fed. Proc. 13, 299.

Slein, M. W., Cori, G. T. \& Cori, C. F. (1950). A comparative study of hexokinase from yeast and animal tissues. J. biol. Chem. 186, 763 .

Smith, E. E. B. \& Mrlus, G. T. (1954). Uridine nucleotide compounds of liver. Biochim. biophys. Acta, 13, 386.

Smith, E. E. B., Milis, G. T., Bernheimer, H. P. \& Austrian, R. (1958a). The formation of uridine pyrophosphoglucuronic acid from uridine pyrophosphoglucose by extracts of a noncapsulated strain of pneumococcus. Biochim. biophys. Acta, 28, 211.

Smith, E. E. B., Milis, G. T., Bernheimer, H. P. \& Austrian, R. (1958b). The presence of an uronic acid epimerase in a strain of pneumococcus type $\mathrm{I}$. Biochim. biophys. Acta, 29, 640. 
Smith, E. E. B., Mills, G. T. \& HARPER, E. M. (1957 a). A comparison of the uridine pyrophosphoglycosyl metabolism of capsulated and non-capsulated pneumococci. J. gen. Microbiol. 16, 426.

Smith, E. E. B., Mirls, G. T., Harper, E. M. \& Galloway, B. (1957b). The cellular polysaccharide of a type II non-capsulated pneumococcus. J. gen. Microbiol. $17,437$.

Strominger, J. L., Kalckar, H. M., Axelrod, J. \& Maxwell, E. S. (1954). Enzymic oxidation of uridine diphosphate glucose to uridine diphosphate glucuronic acid. J. Amer. chem. Soc. 76, 6411.

Strominger, J. L., Maxwell, E. S., Axelrod, J. \& Kalckar, H. M. (1957). Enzymatic formation of uridinediphosphoglucuronic acid. J. biol. Chem. 224, 79.

WyatT, G. R. (1951). Recognition and estimation of 5-methylcytosine in nucleic acids. Biochem. J. 48, 581.

(Received 2 December 1958) 